\title{
Apresentação
}

\section{Linguagem e subjetividade na relação do sujeito com a(s) língua(s)}

A proposta central deste volume temático especial da Revista Letras \& Letras concerne a problematização dos efeitos da articulação e da afetação entre linguagem e subjetividade na relação que o sujeito estabelece com a(s) língua(s) que o constitui(em) enquanto um saber de si e sobre si.

Da perspectiva psicanalítica, a relação com o saber é basilar na constituição subjetiva. É ela que move o sujeito na busca por fazer sentido do desconhecido e do enigmático, processo marcado pela descontinuidade, inquietação e implicação subjetiva. Nesse sentido, a relação de um sujeito com o saber ultrapassa a esfera do conhecimento informacional, cultural, enciclopédico ou mesmo acadêmico, sem, entretanto, prescindir dele.

O conjunto de trabalhos que compõem este número se orienta por uma noção de sujeito instituída por autores franceses da perspectiva discursiva que se deixaram afetar pela visada da psicanálise. Nesse sentido, Pêcheux e Fuchs (1975 [1997], p. 171), se valendo da hipótese do inconsciente oriunda da psicanálise freudiana, apontam para "uma teoria não-subjetiva da constituição do sujeito em sua situação concreta de enunciador", tendo em vista que o sujeito não está na origem dos sentidos, pois só se constitui como sujeito-falante como efeito do assujeitamento à linguagem e às leis simbólicas, na ilusão discursiva de estar na fonte do sentido. Como destaca Baldini (2012), há algo essencial na teorização de Pêcheux: o vínculo indissociável entre constituição do sujeito do discurso e constituição do sentido, bem como a relação indissociável entre ideologia e inconsciente. Essa relação indissociável, que incide na constituição do sujeito e dos sentidos, é destacada por Henry (1977 [2013], p.188), ao afirmar que "o sujeito é sempre, e ao mesmo tempo, sujeito da ideologia e sujeito do desejo inconsciente e isso tem a ver com o fato de nossos corpos serem atravessados pela linguagem antes de qualquer cogitação".

Retomando o título desta apresentação, a relação do sujeito com a(s) língua(s) que o constituem é problematizada a partir do saber ali posto em jogo. Ressaltamos que a relação com o saber é considerada, nessa perspectiva, distinta da relação com o conhecimento, pois remete à incidência de um não-saber sobre a elaboração de um saber do sujeito sobre si e sobre o que 
o circunda ${ }^{1}$. Os trabalhos lacanianos (LACAN, 1992 [1969-70]) propõem o saber como resultante das incidências do Outro sobre o sujeito, tecendo, assim, o inconsciente, e assinalando certos modos de ser e estar no mundo. Não temos acesso a esse saber a não ser pelos seus efeitos sobre nossas posições e, por isso, o psicanalista lhe confere a predicação de ser um não-saber - um saber que não se sabe.

Para se constituir, o saber depende da instauração de um enigma. Freud (1996 [1905]) propôs que esse primeiro mistério remete à curiosidade sobre a origem da vida e sobre a sexualidade, o que sustentaria os movimentos intelectuais da criança desde a sua implicação no conflito edípico. O saber que interessa à psicanálise freudo-lacaniana, portanto, não tem ligação direta com a intelectualidade e aquisição de conhecimentos, mas com os primitivos jogos pulsionais que incidem nesse processo e na articulação da cadeia significante. Essa incidência é responsável por estruturar os movimentos que alguém empreenderá para tecer alguma forma de saber articulado.

Nesse sentido, o saber que imputamos estar na relação de um sujeito com uma língua sobrepuja a esfera do conhecimento, na medida em que ela permite a alguém tecer um saber sobre si e sobre o mundo que jamais se totalizará. Trata-se de um complexo processo de elaboração e apropriação, pois o conhecimento sobre a língua não se traduz em sabê-la. Basta pensar que o fato de alguém "dominar" as regras gramaticais ou saber muitas palavras de uma língua não permite, necessariamente, que possa se enunciar por meio dela. Os investimentos subjetivos dirigidos a ela dependerão não só das práticas discursivo-pedagógicas que visam didatizá-la e torná-la passível de constituir-se em objeto didático, mas, em especial, do quanto o saber ali ensejado poderá interpelar um sujeito em seus já estabilizados modos de gozo ${ }^{2}$. Em outras palavras, o saber da língua a ser aprendida precisa esburacar, de algum modo, as certezas

\footnotetext{
${ }^{1}$ A grafia da expressão "não-saber" em itálico e com hífen marca nossa filiação ao pressuposto de que o processo de aprender, ensinar, conhecer ou qualquer outra ação de um sujeito sobre um objeto, visando a elaborar algo de particular sobre si e sobre ele, convoca a instância do inconsciente.

${ }^{2} \mathrm{O}$ termo gozo é bastante presente no ensino de Lacan e trata, a um só tempo, "da perda inicial, causa da orientação subjetiva ulterior, constitutiva do objeto humano, e das características de estranheza, ausência, radical alteridade e inclusive hostilidade, que a situam no cerne do que se trata de encontrar e não pode ser reencontrado. Assim se encontra apreendido o que é simultaneamente excluído do interior, impensável e que empurra inexoravelmente à repetição" (GEORGES, 2008, p. 146). O gozo, em sua permanente exigência de satisfação, engloba o mais além do princípio do prazer de todo funcionamento pulsional do sujeito do desejo inconsciente. Algo sempre resta irrepresentável e inacessível no gozo, algo que não serve para nada, salvo a sua própria exigência contínua de satisfação. Se algum objeto é considerado, postula Georges (2008, p. 147), "vê-se bem que ele será apenas subsidiário, permutável e contingente". Os modos como o sujeito goza estabelecem um funcionamento subjetivo. Constituem, assim, modalidades de gozo direcionadoras da energia pulsional do sujeito, estruturando, portando, a economia psíquica (MRECH, 1999).
} 
bem entretecidas que constituem as redes de identificação de um sujeito, para que possa se erigir como um enigma digno de receber dele investimento.

Embora, porém, ultrapasse os limites da racionalização e das operações cognitivas, o saber em jogo na relação do sujeito com uma língua não prescinde do conhecimento. Ele constitui a base para que alguém possa se instituir na posição de "Eu sei" ou "Eu não sei", garantindo uma certa estabilidade calcada em uma crença, condição inicial para o saber (MRECH, 1999). Entretanto, o conhecimento não garante a ação subjetiva necessária sobre um objeto, para que dela resulte uma elaboração particular, para que algo desse objeto se torne parte do sujeito, para que um sujeito possa, de algum modo, dele se apropriar. Semelhantemente, a construção particular resultante dos investimentos subjetivos sobre o objeto de saber não passa de semblante, ou seja, "uma forma de saber que é verdadeira, mas que não o é para todo o sempre" (MRECH, 1999, p. 84). Daí a natureza sempre enigmática que perpassa a relação com o saber, porque por mais que se tente, ele não se totaliza, não se deixa capturar, não se unifica. No momento em que é encarado como tal, se reduz ao conhecimento e passa a ser semblante de saber. Afinal, “(...) saber é sempre, por algum lado, crer saber” (LACAN, 1985 [1954-55], p. 58). As formas como o saber não sabido foi tecido e a extensão com a qual marca o sujeito repercutem no modo como ele se posicionará no mundo durante toda a sua vida, como assevera Diniz (2006, s/p): “A relação de um sujeito com o saber, além de incorporar os aspectos objetivos (conhecimento) presentes nos processos educativos e sócio-culturais, supõe, também, aspectos subjetivos marcados pela incidência do inconsciente".

O encontro-confronto com uma língua, seja ela a ensinada na escola como primeira língua, seja ela considerada como estrangeira, constitui mais uma via por meio da qual alguém poderá ter revisitada e/ou ressignificada a mediação que empreende com o mundo. As línguas possibilitam ao sujeito a experiência de encontrar um lugar (ainda que pontual) para si no mundo, ver-se representado nele, de representa-lo e conferir-lhe sentidos. Ela instaura discursividades sobre os objetos, sofre o efeito da subjetividade daqueles que nela se inscrevem e se deixam, no mesmo movimento, nela inscrever. Nesse ponto, a Linguística da Enunciação, proposta por Benveniste, compõe a articulação radical entre linguagem e subjetividade por nós defendida, visto propor que o sujeito se constitui por meio da linguagem, na mediação que ela propicia com o outro/Outro, sendo cada exercício de interlocução um ato único, particular e marcado pela subjetividade em ação, tornando cada enunciação irrepetível e singular (BENVENISTE, 1995 [1966], 2006 [1974]). 
Ainda que recentes, trabalhos que abordam as incidências ou emergências subjetivas na relação do sujeito com as línguas têm trazido considerações relevantes dentro das linhas de pesquisa que se propõem a pensar o ensino-aprendizagem de línguas e seus efeitos nos processos de significação e de subjetivação. Referimo-nos, em especial, à potencialidade de uma língua, enquanto objeto de saber, provocar (des)estabilizações na constituição subjetiva daqueles que se engajam em uma inscrição em sua ordem. Quer seja pela poética, equivocidade, incompletude, ou mesmo, sistematicidade, o embate com uma língua deixa marcas na subjetividade, ao mesmo tempo em que deixa, na língua, marcas da experiência do sujeito com esse objeto, se pensarmos nesse processo sob a perspectiva deleuziana.

Esse modo de se pensar a experiência no ensino-aprendizagem de línguas, temática cara à Linguística Aplicada, em particular, e às Ciências da Linguagem, de modo geral, constituiu uma das investidas analíticas empreendidas no projeto Linguagem e Subjetividade, contemplado pelo programa "Casadinho-PROCAD", financiado pela CAPES, durante o período de 2012-2015. Esse intercâmbio de pesquisas integrou os membros do Grupo de Pesquisa e Estudos sobre Linguagem e Subjetividade (GELS-UFU), Vozes (In)fames: identidade e resistência (UNICAMP) e Semântica do Acontecimento (UNICAMP). Para tanto, esforços conjuntos de pesquisadores aprofundaram uma investigação teórico-analítica sobre a relação entre linguagem e subjetividade, a partir de campos que guardam afinidades epistemológicas, sem perder de vista suas especificidades teórico-metodológicas, a saber: os estudos pecheutianos e foucaultianos sobre o Discurso, a Linguística da Enunciação, a Semântica da Enunciação, a Desconstrução e a Psicanálise. Esses campos têm em comum uma teoria de linguagem que a considera como não toda e o fato de serem afetados por uma noção de subjetividade que a esvazia de toda e qualquer essência prévia, embora uma ilusão de unidade estruturante seja necessária para que alguém possa enunciar. A articulação entre os campos possibilitou uma profícua interlocução para abordar a relação que se propõe entre discurso, subjetividade e ensino enquanto base teórica na constituição e análise de corpora, a fim de discutir a problematização referida.

Nesse sentido, este número "Discurso, Subjetividade e Ensino" acolhe trabalhos que se inscrevem, teoricamente, na articulação epistemológica descrita, para discutir resultados de pesquisas que contemplem a temática e/ou para expor elaborações conceituais resultantes do aprofundamento teórico empreendido durante o projeto e de outros pesquisadores que se interessam por ela. 
A relevância de reunir trabalhos que abordam a temática em tela consiste no deslocamento do vértice sob o qual a relação do sujeito com a(s) língua(s) enquanto objeto(s) de saber é investigado. A articulação discurso-subjetividade enseja a discussão de saídas subjetivas e/ou singulares para os impasses que se materializam no embate com a (des)construção do saber, a problematização de práticas discursivo pedagógicas e políticas tidas como estáveis ou como solucionistas, a análise dos efeitos de possíveis intervenções, a investigação dos efeitos de novos modos de subjetivação que se deixam flagrar no ensinoaprendizagem de línguas, a implicação dos sujeitos envolvidos, dentre outras contribuições.

Assim, os estudos reunidos e divulgados neste número especial contemplam, de modo particular e consequente, a relação entre Discurso, Subjetividade e Ensino, a partir da análise de diferentes materialidades, práticas discursivas e espaços enunciativos que comportam o político na articulação com o histórico e o simbólico.

No artigo que abre este volume, “Apprendre la langue de l'autre”, Patrick Anderson se opõe a uma visão puramente instrumental da linguagem, ao adotar uma perspectiva que se volta para a dimensão sensorial presente no ensino de língua estrangeira. A integração de peças dramáticas ao ensino, sugere o autor, permite acessar o modo como a língua do outro afeta o corpo, através do prazer sentido diante dos sons, do trabalho com a voz, da verbalização e do prazer da projeção discursiva. O autor observa como a língua trabalha o sujeito e como o sujeito trabalha a língua, num movimento de dupla afetação.

No estudo "A construção da subjetividade surda pela falta/presença da língua: uma análise foucaultiana", Márcia Aparecia Amador Máscia e Maria Salomé Soares Dallan analisam o lugar discursivamente construído para o surdo ao longo da história, em várias instâncias sociais. Com base em uma perspectiva foucaultiana, as autoras se lançam à análise de dois fragmentos de discurso - o de "deficiente auditivo" e o de "povo surdo" - que por serem constituídos e legitimados sócio historicamente, podem engendrar (novas) subjetividades surdas. Os variados enfoques dados ao tema do surdo e da surdez, destacam as autoras, produziram múltiplos objetos-sujeito dos discursos que circularam a respeito das consequências do "não-ouvir".

Marluza Terezinha da Rosa, em seu artigo “Imagens não só ilustram; palavras não só descrevem: leitura e efeitos de sentido na tessitura verbo-imagética", propõe uma reflexão sobre o modo como se constroem, linguística e discursivamente, representações sobre o outro/estrangeiro no cenário atual de deslocamentos e de fronteiras entre línguas-culturas, por 
meio da análise de uma fotografia e de três charges cuja temática é o fluxo migratório em direção ao continente europeu nos últimos anos. Pelo viés teórico-conceitual dos estudos discursivo-desconstrutivistas, a autora relaciona a problemática em questão aos desafios que constituem o ensino-aprendizagem da leitura.

Ancorando-se em questões teóricas fundamentais da Análise de Discurso pecheutiana, que considera o atravessamento da psicanálise freudo-lacaniana em seu quadro epistemológico, Maralice de Souza Neves, no trabalho intitulado "A escuta de uma professora de língua inglesa em educação continuada: por que não sustentar a posição de louca?”, se volta para o espaço discursivo da Educação Continuada de professores de inglês do ensino básico. Privilegiando o que há de insondável no Real para além do Simbólico e do Imaginário, a autora oferece uma escuta singular e consequente para um relato de uma professora sobre um acontecimento que diz respeito a um de seus alunos e que a afetou subjetivamente, causando-lhe mal-estar e inibindo um estilo que poderia lhe ser útil, ainda que excessivo.

O trabalho de Valdeni da Silva Reis, "Recusas e deslocamentos subjetivos de duas professoras de inglês em contexto encarcerado", aborda a forma como duas professoras, que atuam em unidades socioeducativas para adolescentes em conflito com a lei, constituem seu ser, dizer e fazer como professoras de inglês. Partindo das entrevistas realizadas com essas professoras, bem como de teorias em torno da formação do professor de língua inglesa e de noções como tempo, espaço e memória a autora se lança à compreensão do modo como as professoras constituem, nesse espaço adverso, seu posicionamento e possível redimensionamento discursivo e subjetivo.

Carmen Lucia Hernandes Agustini e Eduardo Alves Rodrigues, no artigo "O processo de reescrita de textos no espaço político-simbólico escolar: rasura, subjetividade, (neo)liberalismo", propõem uma relevante discussão sobre os efeitos que a política financeira (neo)liberalista produz sobre o modo como a educação acontece no espaço político-simbólico da escola formal, sobretudo no âmbito do Ensino Médio e do Ensino da Produção de Textos em Língua Portuguesa. Do ponto de vista da Análise de Discurso, este estudo problematiza o efeito de afrouxamento produzido pelo (neo)liberalismo sobre a relação professor-alunoconhecimento.

Em "Sujeitos entre-línguas em contextos de imigração: incidências na subjetividade", Beatriz Maria Eckert-Hoff se propõe a analisar escritas de si, por meio de recortes extraídos de Cartas enviadas por imigrantes alemães e por seus descendentes a seus familiares que 
permaneceram na Alemanha. As cartas datadas do século XIX e XX foram coletadas em arquivos públicos e privados da Alemanha. Tendo como aporte teórico a Análise de Discurso francesa, que se entremeia com alguns fios da Psicanálise, a autora salienta o entrelaçamento das línguas na constituição da subjetividade de sujeitos em situação de imigração.

Natalia Mariloli Santos Giarola, no artigo intitulado "Auto representações de uma professora de língua inglesa", a partir da teoria do discurso atravessada pela psicanálise freudolacaniana, buscou compreender como uma professora da rede pública, participante do projeto ConCol (Continuação Colaborativa), da Universidade Federal de Minas Gerais (UFMG), se representa como professora de língua inglesa e como isso afeta sua prática pedagógica. A autora propõe problematizações significativas acerca da formação de professores, ao discutir temas que podem fazer com que os docentes se confrontem com os significantes que eles se atribuem ao se dizerem professores e falantes de língua estrangeira.

No estudo "Escrita e formação do espírito científico: o trabalho invisível do orientador", Claudia Rosa Riolfi e Emari Andrade buscam dar a ver o trabalho invisível do orientador que ajuda a fazer a passagem de um trabalho calcado no senso comum para um modus operandi fundado na cientificidade. Ancoradas nos postulados de Bachelard sobre a formação do espírito científico, as pesquisadoras se voltam para os modos como o orientador incide na relação do aluno com o saber. Para responder qual é a participação do orientador no processo de elaboração do trabalho científico, as autoras partiram de uma teoria da subjetividade na qual o sujeito, definido como efeito de linguagem, não é determinado pela realidade empírica, mas pelo modo como a linguagem incidiu em seu corpo.

Fernanda Peçanha Carvalho, no artigo "Representações sobre ensino de espanhol como língua estrangeira: entre a possibilidade e a contingência", aborda os efeitos das representações de professores sobre o ensino de espanhol e na constituição subjetiva do professor. O corpus de análise foi constituído por entrevistas semiestruturadas, realizadas com cinco professores de espanhol de escolas públicas e privadas de Belo Horizonte e cidades metropolitanas. Partindo dos estudos pecheutianos numa interface com a psicanálise lacaniana, os gestos de interpretação empreendidos permitiram identificar, nos dizeres dos professores, representações permeadas por rastros de singularidade, além de significantes que configuram o ensino de espanhol nos circuitos da contingência e da possibilidade.

No artigo, "Sentidos no texto: uma análise de "neologismo" de Bandeira", Eduardo Guimarães se volta para o poema "Neologismo", de Manuel Bandeira, para colocar em pauta 
uma questão sobre a língua e sobre sua enunciação. O autor propõe um modo de olhar para o discurso poético que produz implicações para o ensino e para subjetividade, uma vez que o neologismo pode ser compreendido como algo subjetivo que deixa pistas sobre o modo como o sentido toca o sujeito em sua produção textual.

Vania Maria Lescano Guerra e Eliane Francisca Alves da Silva, no artigo que se intitula "Sujeitos surdos e discurso: a construção identitária e as relações de ensino", a partir de uma perspectiva discursiva da linguagem, observam as interferências da Língua Brasileira dos Sinais na marcação de tempo e em outros aspectos da Língua Portuguesa, mediante análise de mensagens de surdos trocadas via inbox, pela rede social Facebook. As autoras analisam os aspectos linguísticos da LIBRAS, a estrutura dos sinais que dão forma às formulações dos surdos e qual a relação que se estabelece entre estes dois sistemas linguísticos tão distintos: a Língua de Sinais e a Língua Portuguesa, no processo de ensino aprendizagem desses sujeitos.

Angela Derlise Stübe e Tany Aline Folle, no artigo "Formações imaginárias sobre língua inglesa pessoal e profissional" buscam resgatar o imaginário sobre língua inglesa que se inscreve em narrativas de sujeitos-professores residentes na região de abrangência da UFFS, Campus Chapecó - SC, graduados em Letras, docentes no Ensino Fundamental I, II e no Ensino Médio. Inscritas em uma perspectiva discursiva, as autoras observam que as formações imaginárias sobre a língua inglesa se constituem por traços que apontam rupturas e tensões, pois ultrapassam o nível linguístico, para envolver aspectos identitários, históricos, sociais, políticos e educacionais.

No artigo intitulado "O papel conservador da renovação terminológica: reflexões sobre a expressão ‘expectativas de aprendizagem’”, Peterson José Oliveira, valendo-se de conceitos da Semântica da Enunciação e de análises conjunturais sobre a escola e a educação, propõe uma análise de partes de um documento da secretaria de Educação do Estado de São Paulo, no qual a expressão 'expectativas de aprendizagem' aparece como jargão pedagógico. O autor destaca a imprecisão no uso do termo, bem como sua equivalência semântico-discursiva a expressões como objetivos de ensino, o que produz um esvaziamento conceitual e destitui a autonomia dos professores em relação aos conteúdos ministrados.

Encerrando este volume, o artigo de Arabela Vieira dos Santos Silva Franco, "Ser ou não ser bilíngue: Os posicionamentos subjetivos de uma professora de inglês diante do Outro", propõe uma abordagem psicanalítica para analisar como cada sujeito se inscreve discursivamente como sujeito bilíngue. À luz das teorias da significação e dos quatro discursos 
esquematizadas por Lacan, a autora analisa alguns dizeres de uma professora a respeito do tema bilinguismo, destacando sua relação com a fala em língua inglesa. A autora salienta a importância de se considerar o impossível na relação com as línguas e o modo singular como cada um lida com sua falta constitutiva.

A proposta deste número especial da Revista Letras \& Letras representa, por fim, uma oportunidade de divulgar os resultados de um diálogo profícuo e heterogêneo estabelecido entre pesquisadores reconhecidos dos Estudos Enunciativo-Discursivos, da Linguística, da Linguística Aplicada, da Semântica Histórica da Enunciação, ou seja, de estudos que se inserem no âmbito das Ciências da Linguagem.

Agradecemos aos coordenadores do projeto Casadinho, Ernesto Sérgio Bertoldo, Cármen Lúcia H. Agustini e Carla Tavares, pela iniciativa que propiciou intenso intercâmbio e discussões acadêmicas; e aos pesquisadores que nos confiaram seus textos e suas reflexões que, certamente, provocarão problematizações relevantes não só acerca do processo de ensinoaprendizagem de línguas, mas sobre o modo como a subjetividade se constitui na/pela lingua(gem) e sobre os efeitos produzidos por práticas discursivo-enunciativas em nossa sociedade. Também não poderíamos deixar de agradecer o apoio que recebemos do editor Guilherme Fromm, ao longo de toda a confecção deste volume. Desejamos a todos uma boa e instigante leitura!

As Organizadoras: Carla Nunes Vieira Tavares* Juliana Santana Cavallari**

\section{Referências}

BALDINI, L. J. S. Discurso e cinismo. In: MARIANI, B.; MEDEIROS, V. (Orgs.). Discurso e...: ideologia, memória, desejo, movimentos sociais, cinismo, corpo, witz, rede eletrônica, língua materna, poesia, cultura, mídia, educação, tempo, (homo)sexualidade. Rio de Janeiro: 7Letras; Faperj, 2012. p. 50-58.

\footnotetext{
* Professora no Instituto de Letras e Linguística (ILEEL) e do Programa de Pós-Graduação em Estudos Linguísticos (PPGEL) da Universidade Federal de Uberlândia (UFU); com doutorado em Linguística Aplicada pela Universidade Estadual de Campinas (UNICAMP) e em Ciências da Linguagem pela Universidade de Franche-Comté, FR; coordenadora do Grupo de Estudos e Pesquisa em Linguagem e Subjetividade (GELS).

** Professora do Programa de Pós-Graduação em Ciências da Linguagem da Universidade do Vale do Sapucaí (UNIVAS); com doutorado em Linguística Aplicada pela Universidade Estadual de Campinas (UNICAMP) e pósdoutorado na área de Tradução, pela mesma instituição; líder do Grupo de Pesquisa Subjetividades e Identificações: efeitos de (d)enunciação (GPSI).
} 
BENVENISTE, E. Problèmes de linguistique general I. Paris, FR : Gallimard, 1995.

Problemas de lingüística geral. 2.ed. Campinas: Pontes, 2006.

DINIZ, M. A relação com o saber para a psicanálise. In: Psicanálise, educação e transmissão, v.6., 2006, São Paulo, SP. Proceedings online... Disponível em http://www.proceedings.scielo.br/scielo.php?script=sci arttext\&pid=MSC0000000032006000 $\underline{100049 \& \operatorname{lng}=\mathrm{en} \& \mathrm{nrm}=\mathrm{abn}}$. Acesso em: 30, Maio, 2016.

FREUD, S. Três ensaios sobre a teoria da sexualidade. In: . Obras Completas Ed. Standard Brasileira. Rio de Janeiro: Imago, 1996. pp. 118-160.

GEORGES, P. Do gozo. In: Scilicet: Os objetos a na experiência psicanalítica. Associação Mundial de Psicanálise. Rio de Janeiro: Contra Capa Livraria, 2008, p. 146-148.

LACAN, J. O seminário livro 2: o eu na teoria de Freud e na técnica da psicanálise. Rio de Janeiro, RJ: Jorge Zahar, 1985.

O seminário livro 17: o avesso da Psicanálise. Rio de Janeiro, RJ: Jorge Zahar, 1992.

MRECH, L. M. Psicanálise e educação: novos operadores de leitura. São Paulo: Pioneira, 1999.

HENRY, P. A ferramenta Imperfeita: língua, sujeito e discurso. Tradução de Maria Fausta P. de Castro, $2^{\mathrm{a}}$ ed. Campinas: Editora da Unicamp, 2013.

PÊCHEUX, M.; FUCHS, C. A propósito da análise automática do discurso: atualizações e perspectivas (1975). In: GADET, F.; HAK, T. (Orgs). Por uma análise automática do discurso: uma introdução à obra de Michel Pêcheux. Tradutores Bethania S. Mariani, Eni P. Orlandi [et al.]. 3ed. Campinas: Editora da Unicamp, 1997. 